\title{
Effects of Three Different Hip Positions in Frontal Plane on Activity of Abdominal Muscles During Active Straight-Leg Raise
}

\author{
Tae-lim Yoon ${ }^{1}, \mathrm{MA}, \mathrm{PT}, \mathrm{Ki}-$ song $\mathrm{Kim}^{2}, \mathrm{PhD}, \mathrm{PT}$ \\ ${ }^{1}$ Applied Kinesiology and Ergonomic Technology Laboratory, \\ Dept. of Physical Therapy, The Graduate School, Yonsei University, \\ ${ }^{2}$ Research Institute for Basic Sciences, Dept. of Physical Therapy, College of Natural Science, Hoseo University
}

\begin{abstract}
Active straight-leg raise (ASLR) is a physical evaluation procedure to test lumbar spine stability. Several previous studies have reported various methods to control the activation of abdominal muscles during ASLR. We investigated the effects of three different hip positions in frontal plane on abdominal muscles to increase or decrease the difficulty level of lumbar spine stability exercise during ASLR in pain free subjects. Eleven young and healthy subjects voluntarily participated in this study (6 men, 5 women; mean age $=24.0 \pm 1.2$ years, height $=160.0 \pm 7.3 \mathrm{~cm}$, weight $=55.0 \pm 10.6 \mathrm{~kg}$, body mass index $\left.=21.5 \pm 2.3 \mathrm{~kg} / \mathrm{m}^{2}\right)$. The subjects had three trials on each ASLR with hip $10^{\circ}$ adduction, neutral hip, and hip $30^{\circ}$ abduction. Separate repeated-measures analysis of variance (ANOVA) and the post hoc Bonferroni tests (with a $=.05 / 3=.017$ ) were performed for each muscle among the three different hip positions in frontal plane (ASLR with hip $10^{\circ}$ adduction, neutral hip, and hip $30^{\circ}$ abduction). The ipsilateral external oblique (EO), contralateral EO, ipsilateral internal oblique/transverse abdominis (IO/TrA), and contralateral IO/TrA were significantly greater in ASLR with hip $30^{\circ}$ abduction compared with ASLR with hip $10^{\circ}$ adduction. Also, the ipsilateral EO, contralateral EO, and ipsilateral IO/TrA were significantly greater in ASLR with hip $30^{\circ}$ abduction compared with ASLR with neutral hip. These results suggest that ASLR with hip $30^{\circ}$ abduction and neutral would be useful method to strengthen the EO and IO/TrA. And, ASLR with hip $10^{\circ}$ adduction would be effective in early stages of lumbar stabilization program due to low activation of $\mathrm{EO}$ and $\mathrm{IO} / \mathrm{Tr}$ A during maintaining of ASLR position with low load.
\end{abstract}

Key Words: Electromyograph; Lumbar spine stabilization; Strengthening exercise.

\section{Introduction}

Active straight-leg raise (ASLR) is a physical evaluation procedure with load transfer through the pelvis to test lumbar spine stability (Liebenson et al, 2009; Mens et al, 2001; Mens et al, 2002; Mens et al, 1999; O'Sullivan et al, 2002). A positive sign of the ASLR has been confirmed with the feeling of heaviness of the raising leg, pain in lumbopelvic legion, weakness on manual resistance, or lumbar axial rotation which indicates inadequate lumbar control (Liebenson et al, 2009; Mens et al, 2001; Mens et al,
2002; O'Sullivan et al, 2002).

Various previous studies have inspected motor control strategies during ASLR to improve the understanding of the motor control mechanisms related with load transference through the pelvis (Beales et al, 2009; Hu et al, 2012; Liebenson et al, 2009; Mens et al, 1999; O'Sullivan et al, 2002; Park et al, 2013; Teyhen et al, 2009). Increased activation of abdominal muscles results in more lumbar spine stability under a given load (Brown and McGill, 2005). Particularly, rectus abdominis (RA), external oblique (EO), internal oblique (IO), and transverse abdominis

Corresponding author: Ki-song Kim kskim68@hoseo.edu 
(TrA) has been identified as key muscles for lumbar spine stability by pressing the iliac bones against the sacrum (Kim et al, 2011; Snijders et al, 1993; Vera-Garcia et al, 2007).

Several previous studies have claimed that lumbar spine stability can be enhanced with several methods (using of pelvic tilt, tactile stimulation, abdominal hollowing, weight, abdominal bracing, raising leg, gym ball, or wobble board). These methods used to control the difficulty level of lumbar spine stability exercises and compensatory movement of the lumbopelvic system (Garcia-Vaquero et al, 2012; Hu et al, 2012; Kavcic et al, 2004; McGill and Karpowicz, 2009; Park et al, 2013; Souza et al, 2001; Stevens et al, 2006). However, the level of lumbar spine stability was not fully investigated. And, there was no study using the three different hip positions in frontal plane (hip $10^{\circ}$ adduction, neutral hip, and hip $30^{\circ}$ abduc $^{-}$ tion) to increase or decrease the difficulty level of lumbar spine stability exercise during ASLR.

Therefore, the purposes of this study was to investigate the effects of three different hip positions in frontal plane (hip $10^{\circ}$ adduction, neutral hip, and hip $30^{\circ}$ abduction) on activation of abdominal muscles in pain free subjects. This would help to clarify motor control strategies under various loads lumbar spine stability during ASLR. The hypothesis was that the three different hip positions in frontal plane would change the activation of abdominal muscles during ASLR in pain free subjects.

\section{Methods}

\section{Subjects}

Eleven young and healthy subjects voluntarily participated in this study (6 men, 5 women; mean age $=24.0 \pm 1.2$ years, height $=160.0 \pm 7.3 \quad \mathrm{~cm}$, weight $=55.0 \pm 10.6 \mathrm{~kg}$, body mass index $=21.5 \pm 2.3 \mathrm{~kg} /$ $\mathrm{m}^{2}$ ). The volunteers were included if they had no limitation of hip $10^{\circ}$ adduction and hip $30^{\circ}$ abduction. The volunteers were excluded if they had a history of low back pain and lower extremity injuries, leg-length discrepancy, marked kyphosis or scoliosis, or neurologic disease (Kim et al, 2011; Park et al, 2013). The determining of dominance was investigated based on asking the participant to kick a soccer ball (Jacobs et al, 2005; Sung, 2013). All participants were right-leg dominant. All subjects provided written informed consent in agreement with the guidelines of the Yonsei University Wonju Institutional Review Board.

\section{Procedure}

The subjects had 20 min of familiarization session on ASLR with hip $10^{\circ}$ adduction, neutral hip, and hip $30^{\circ}$ abduction under the supervision of primary researcher. The EMG activity was measured three times on each ASLR with hip $10^{\circ}$ adduction, neutral hip, and hip $30^{\circ}$ abduction. To randomize the test order, we used three cards, each marked with one of the exercises. Each subject was asked to draw a card from a box to exclude any potential effects of measurement order. A target bar was placed $20 \mathrm{~cm}$ above the mat. Each subject raised their dominant leg, touched the target bar without bending the knee (Park et al, 2013), and maintained contact with the target bar for $5 \mathrm{~s}$. EMG data were collected for $5 \mathrm{~s}$ at the end test position. The middle $3 \mathrm{~s}$ of collected data were averaged for statistical analysis. The participants were given a 5 -min rest between test conditions to prevent muscular fatigue (Stevens et al, 2007).

ASLR with hip $10^{\circ}$ adduction, neutral hip, and hip $30^{\circ}$ abduction

The subject assumed a supine position on a therapeutic mat with the upper trunk, pelvis, and lower extremity in a straight line. Both arms were crossed on the subject's chest to prevent pushing the ground with their hands. The subject was asked to perform the ASLR in the supine position until they reached the target bar with condition of hip $10^{\circ}$ adduction, neutral hip, and hip $30^{\circ}$ abduction (Figure 1). A uni- 

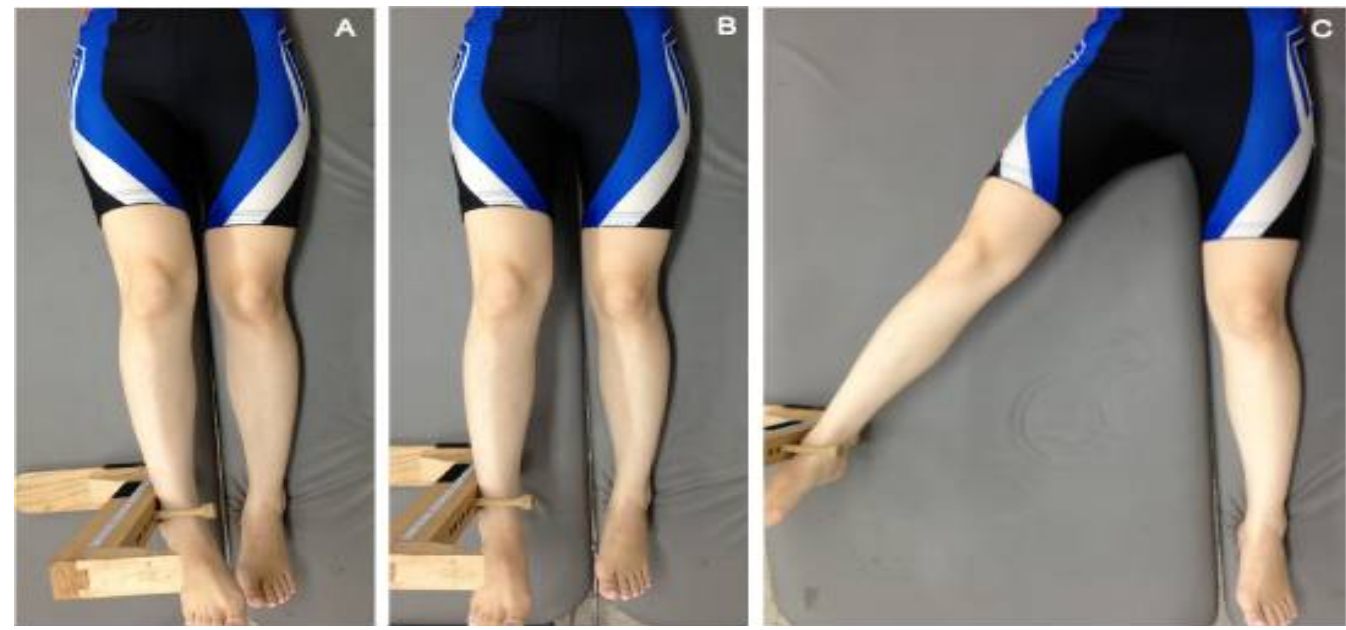

Figure 1. The active straight-leg raise in the supine position until they reached the target bar with condition in hip $10^{\circ}$ adduction, neutral hip, and hip $30^{\circ}$ abduction (A: hip $10^{\circ}$ adduction, B: neutral hip, C: hip $30^{\circ}$ abduction).

versal goniometer was used to measure the three different hip positions in frontal plane (hip $10^{\circ}$ adduction, neutral hip, and hip $30^{\circ}$ abduction) at the frontal plane and determine the position of target bar. Under this condition, the subjects were instructed to, "hold your position on the mat without moving your pelvis while you raise your dominant leg to touch the target bar by brushing the pillar of target bar with the later side of ankle to maintain the hip position in frontal plane" in each condition. The primary researcher was monitoring the compensation of pelvis motion.

\section{Electromyography}

Surface EMG was used to measure activity of abdominal muscles. The EMG data were collected bilaterally from the RA (2 cm lateral to the umbilicus), EO (directly above the ASIS, in direct line with the umbilicus, approximately $12 \sim 15 \mathrm{~cm}$ from the umbilicus), and IO/TrA muscles (halfway between the ASIS of the pelvis and the midline, just superior to the inguinal ligament) (Marshall and Murphy, 2003). The previous study stated that the EMG signal obtained from an electrode inferior to the anterior-superior iliac spine represents the combined $\mathrm{ac}^{-}$ tivity of the IO and TrA (Marshall and Murphy, 2003). The signal representing IO/TrA accurately demonstrates the functional activity of the muscle (Marshall and Murphy, 2003). The skin was shaved, sanded, and swabbed with alcohols-oaked cotton before electrode placement to minimize skin resistance. Disposable $\mathrm{Ag} / \mathrm{AgCl}$ surface electrodes were positioned parallel to the muscle fibers with a center-to-center spacing of $2 \mathrm{~cm}$. using the Tele-Myo 2400T EMG instrument with a wireless telemetry system (Noraxon Inc., AZ, USA). EMG data were collected at the sampling rate of $1000 \mathrm{~Hz}$ and analyzed with Myo-Research Master Edition 1.06 XP software (Noraxon Inc., AZ, USA). The raw signal in EMG was filtered using a digital band-pass filter (Lancosh FIR) between 20 and $400 \mathrm{~Hz}$ to eliminate movement artifacts, and a $60 \mathrm{~Hz}$ notch filter was used to minimize electrical noise. Root-mean-square (RMS) values were calculated with a moving window of $50 \mathrm{~ms}$. For normalization, the RMS of a $5 \mathrm{~s}$ maximal voluntary isometric contraction (MVIC) was measured three times per the abdominal muscles to provide a basis for EMG signal amplitude normalization. For the RA, the subject was positioned supine in a hook-lying position with the feet supported and the thoracolumbar spine maximally flexed (curl-up position). Manual resistance was applied to the subject's shoulders in the direction of trunk extension. For the EO and the IO/TrA mus ${ }^{-}$ 
cles, the subject was supine in a hook-lying position with feet flat on the support surface. The trunk was maximally flexed and rotated to the left, with manual resistance at the shoulders applied in the direction of trunk extension and right rotation. For the other side, the subject was supine in a hook-lying position with the trunk flexed and maximally rotated to the right. Manual resistance was applied at the shoulders in the direction of trunk extension and left rotation (Escamilla et al., 2006).

We used middle $3 \mathrm{~s}$ of collected data to determine the mean amplitude of MVIC. The normalized muscle activity was presented as a percentage of the MVIC (Kim et al, 2011; Park et al, 2013).

\section{Statistical analysis}

Kolmogorov-smirnov Z-tests were performed to assess the normality of distribution. The independent variables were ASLR conditions (ASLR with hip $10^{\circ}$ adduction, neutral hip, and hip $30^{\circ}$ abduction). The dependent variables were EMG activity of each abdominal muscle. Statistical significance was set at .05. Separate analysis of variance (ANOVA) and the post hoc Bonferroni tests (with $a=.05 / 3=.017$ ) were performed for each muscle among the three different hip positions in frontal plane (ASLR with hip $10^{\circ}$ adduction, neutral hip, and hip $30^{\circ}$ abduction). Statistical analysis was performed with SPSS ver. 18.0 for Windows (SPSS Inc., Chicago, IL).

\section{Results}

All dependent variables were established to approximate a normal distribution (Kolmogorov-smirnov $Z$-test, $\mathrm{p}>$.05). The normalized EMG data and the results of the statistical analyses are shown in Figure 2. There was no significant difference in the ipsilateral RA ( $\mathrm{F}=3.641, \mathrm{p}=.069)$ and contralateral RA $(\mathrm{F}=2.910, \mathrm{p}=.106)$. There were significant differences in activation of the ipsilateral $\mathrm{EO}(\mathrm{F}=10.362, \mathrm{p}=.005)$, contralateral EO $(\mathrm{F}=10.115, \mathrm{p}=.005)$, the ipsilateral
$\mathrm{IO} / \operatorname{TrA}(\mathrm{F}=9.868, \mathrm{p}=.005)$, and contralateral $\mathrm{IO} / \operatorname{Tr} \mathrm{A}$ $(\mathrm{F}=5.101, \mathrm{p}=.033)$ in ASLR with three different hip positions in frontal plane. The ipsilateral EO, contralateral EO, ipsilateral $\mathrm{IO} / \mathrm{TrA}$, and contralateral $\mathrm{IO} / \operatorname{TrA}$ were significantly greater in ASLR with hip $30^{\circ}$ abduction compared with ASLR with hip $10^{\circ}$ adduction. Also, the ipsilateral EO, contralateral EO, and ipsilateral IO/TrA were significantly greater in ASLR with hip $30^{\circ}$ abduction compared with ASLR with neutral hip. In all abdominal muscles, there was no significant difference between ASLR with hip $10^{\circ}$ adduction and neutral hip.

\section{Discussion}

The aim of this study was to investigate the effects of three different hip positions in frontal plane on activation of abdominal muscles in pain free subjects. There was no significant difference in the bilateral RA. The ipsilateral EO, contralateral EO, ipsilateral $\mathrm{IO} / \operatorname{Tr} \mathrm{A}$, and contralateral $\mathrm{IO} / \mathrm{TrA}$ were significantly greater in ASLR with hip $30^{\circ}$ abduction compared with ASLR with hip $10^{\circ}$ adduction. Also, the ipsilateral EO, contralateral EO, and ipsilateral IO/TrA were significantly greater in ASLR with hip $30^{\circ}$ abduction compared with ASLR with neutral hip. In all abdominal muscles, there was no significant difference between ASLR with hip $10^{\circ}$ adduction and neutral hip. These result partially support our hypothesis was that the three different hip positions in frontal plane would change the activation of abdominal muscles during ASLR in pain free subjects.

There was no significant difference in the bilateral $\mathrm{RA}$. This result may imply that RA did not have a direct functional role in sustaining ASLR in different hip positions in frontal plane in healthy subjects. A previous study also reported that rectus abdominis showed no functional role during isometric axial ro $^{-}$ tation of the trunk ( $\mathrm{Ng}$ et $\mathrm{al}, 2001$ ).

The bilateral EO and IO/TrA were significantly greater in ASLR with hip $30^{\circ}$ abduction compared 


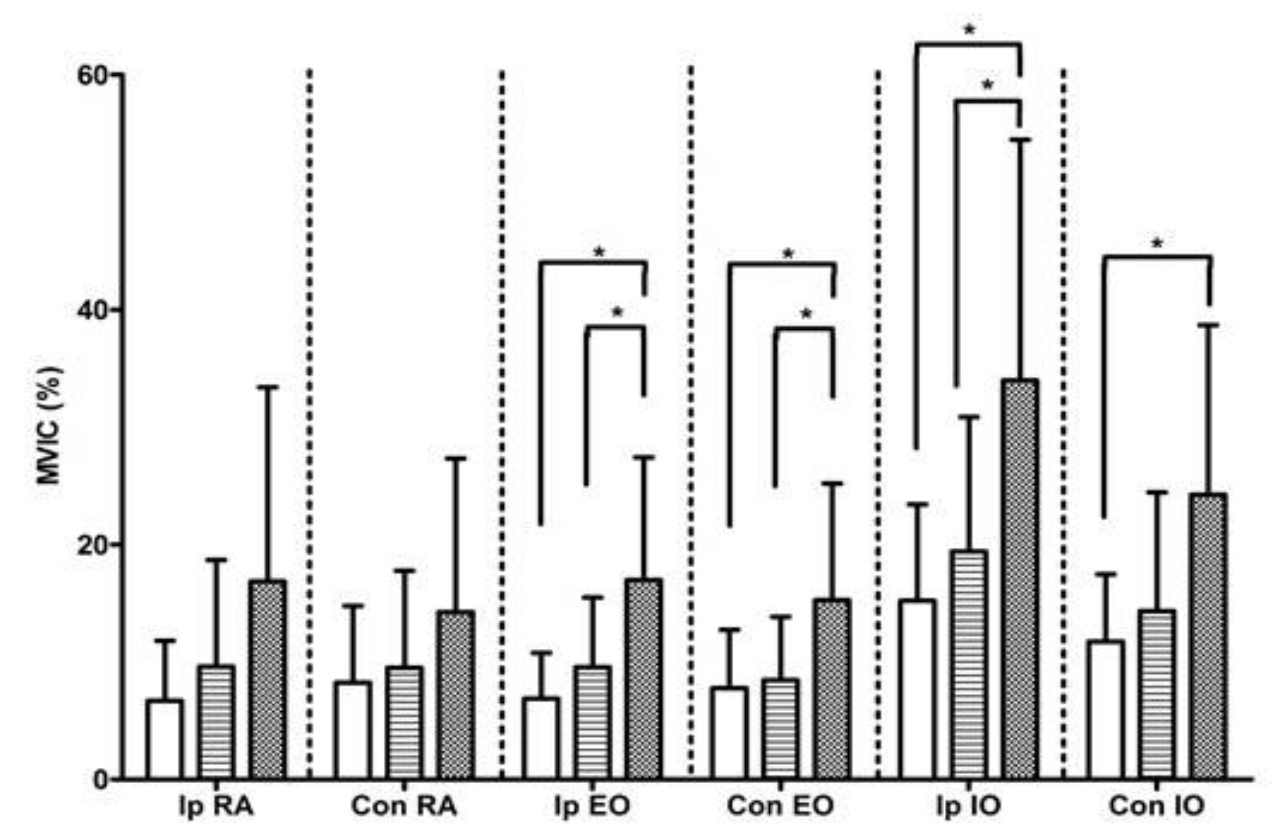

Figure 2. Maximal voluntary isometric contraction in the activity of abdominal muscles during ASLR with hip 10 adduction, neutral hip, and hip $30^{\circ}$ abduction (RA: rectus abdominis; EO: external oblique abdominis; IO/TrA: internal oblique abdominis/ transverse abdominis; Ip: ipsilateral; Con: contralateral; * significant difference at $\mathrm{p}=.017$ ).

with ASLR with hip $10^{\circ}$ adduction. ASLR with hip $30^{\circ}$ abduction would increase the rotational moment arm of the lifted lower limb during ASLR; thus, increased rotational moment arm from the hip joint is likely to require enhanced muscle activation of $\mathrm{bi}^{-}$ lateral $\mathrm{EO}$ and $\mathrm{IO} / \mathrm{TrA}$ compared with ASLR with hip $10^{\circ}$ adduction. A previous study also presented that abdominal muscle ( $\mathrm{EO}$ and $\mathrm{IO} / \operatorname{TrA}$ ) activity was significantly higher with weight load (Hu et al, 2012). The researcher claimed that the activity of abdominal muscles may also rotate the pelvis posteriorly, and thus contribute to counteracting the forward rotation of the ipsilateral ilium which is caused by load transfer from raised leg (Hu et al, 2012). Previous studies also reported that $30^{\circ}$ hip abduction would change the location of muscle attachment and joint position which are important in effective motion production to generate the torque or a turning $\mathrm{mo}^{-}$ ment (Henderson et al, 2011; Kang et al, 2013). Therefore, our results suggest that ASLR with hip $30^{\circ}$ abduction would be useful method to strengthen the $\mathrm{EO}$ and IO/TrA compared to other two conditions for later stages of lumbar stabilization program.

Besides, ASLR with hip $10^{\circ}$ adduction produced less activation of the $\mathrm{EO}$ and $\mathrm{IO} / \mathrm{TrA}$ when $\mathrm{com}^{-}$ pared ASLR with hip $30^{\circ}$ abduction. The less activation of the $\mathrm{EO}$ and $\mathrm{IO} / \mathrm{TrA}$ would result in $\mathrm{de}^{-}$ crease of moment arm from the hip joint. A previous study reported that low load has benefits of reducing chance of pain and reflex inhibition, and restoring joint stabilization (Richardson and Jull, 1995). Consequently, ASLR with hip $10^{\circ}$ adduction would be effective in early stages of lumbar stabilization program due to low activation of $\mathrm{EO}$ and $\mathrm{IO} / \operatorname{Tr} \mathrm{A}$ during maintain ASLR position with low load. 
The ipsilateral EO, contralateral EO, and ipsilateral IO/TrA were significantly greater in ASLR with hip $30^{\circ}$ abduction compared with ASLR with neutral hip. However, there was no significant difference between ASLR with hip $30^{\circ}$ abduction and ASLR with neutral hip in contralateral IO/TrA. These result indicated that ASLR with hip $30^{\circ}$ abduction did not influenced significantly to the contralateral IO/TrA compared with ipsilateral IO/TrA. In a previous study, greater activation in ipsilateral of the abdominal wall (IO/TrA) was shown with increasing of axial load on the side of the raising leg during ASLR (Beales et al, 2009). In addition, relatively symmetrical pattern of EO activation was shown during ASLR with hip 10 adduction, neutral hip, and hip $30^{\circ}$ abduction. A researcher insisted that $\mathrm{EO}$ might have not used to counteract the given axial loan to pelvis in transverse plane (Hu et al, 2012).

This study has several limitations. First, we did not measure the kinematic data of pelvic motion as indications of lumbar spine stability. Second, we only recruited healthy and young Korean; thus, our findings cannot be generalized to other populations. Thirdly, no symptomatic group was used. Further studies are needed to inspect the effect of three different hip positions in frontal plane on activity of abdominal muscles during ASLR with mechanical low-back pain group. Also, longitudinal study of the effect of three different hip positions in frontal plane on activity of abdominal muscles during ASLR should be required.

\section{Conclusion}

The aim of this study was to investigate the effects of three different hip positions in frontal plane on activation of abdominal muscles in pain free subjects. The ipsilateral EO, contralateral EO, ipsilateral IO/TrA, and contralateral IO/TrA were significantly greater in ASLR with hip $30^{\circ}$ abduction compared with ASLR with hip $10^{\circ}$ adduction. These results suggest that ASLR with hip $30^{\circ}$ abduction would be useful method to strengthen the $\mathrm{EO}$ and $\mathrm{IO} / \mathrm{TrA}$ for improving the lumbar spine stability. And, ASLR with hip $10^{\circ}$ adduction would be effective in early stages of lumbar stabilization program due to low activation of $\mathrm{EO}$ and $\mathrm{IO} / \mathrm{Tr} \mathrm{A}$ during maintaining ASLR position with low load.

\section{References}

Beales DJ, O'ullivan PB, Briffa NK. Motor control patterns during an active straight leg raise in pain-free subjects. Spine (Phila Pa 1976). 2009; 34(1):E1-E8.

Brown SH, McGill SM. Muscle force-stiffness characteristics influence joint stability: A spine example. Clin Biomech (Bristol, Avon). 2005; 20(9):917-922.

Escamilla RF, McTaggart MS, Fricklas EJ, DeWitt R, Kelleher P, Taylor MK, et al. An electromyographic analysis of commercial and common abdominal exercises: implications for $\mathrm{re}^{-}$ habilitation and training. J Orthop Sports Phys Ther. 2006;36:45-57.

García-Vaquero MP, Moreside JM, Brontons-Gil E, et al. Trunk muscle activation during stabilization exercises with single and double leg support. J Electromyogr Kinesiol. 2012;22(3): 398-406.

Henderson, ER., Marulanda, GA, Cheong, D, Temple, HT, \& Letson, GD. Hip abductor moment arm a mathematical analysis for proximal femoral replacement. J Orthop Surg Res. 2011:25(6):6.

$\mathrm{Hu}$ H, Meijer OG, Hodges PW, et al. Understanding the active straight leg raise (ASLR): An electromyographic study in healthy subjects. Man Ther. 2012;17(6):531-537.

Jacobs C, Uhl TL, Seeley M, et al. Strength and fatigability of the dominant and nondominant hip abductors. J Athl Train. 2005;40(3):203-206.

Kang SY, Jeon HS, Kwon OY, et al. Activation of 
the gluteus maximus and hamstring muscles during prone hip extension with knee flexion in three hip abduction positions. Man Ther. 2013; 18(4):303-307.

Kavcic N, Grenier S, McGill SM. Quantifying tissue loads and spine stability while performing commonly prescribed low back stabilization exercises. Spine (Phila Pa 1976). 2004;29(20): 2319-2329.

Kendall FP, McCreary EK, Provance PG. Muscles Testing and Function with Posture and Pain. 5th ed. Baltimore, MD, Lippincott williams \& wilkins, 2005;176-182.

Kim SJ, Kwon OY, Yi CH, et al. Comparison of abdominal muscle activity during a single-legged hold in the hook-lying position on the floor and on a round foam roll. J Athl Train. 2011; 46(4):403-408.

Liebenson C, Karpowicz AM, Brown SH, et al. The active straight leg raise test and lumbar spine stability. PM R. 2009;1(6):530-535.

Marshall P, Murphy B. The validity and reliability of surface emg to assess the neuromuscular $\mathrm{re}^{-}$ sponse of the abdominal muscles to rapid limb movement. J Electromyogr Kinesiol. 2003;13(5): 477-489.

McGill SM, Karpowicz A. Exercises for spine stabilization: Motion/motor patterns, stability progressions, and clinical technique. Arch Phys Med Rehabil. 2009;90(1):118-126.

Mens JM, Vleeming A, Snijders CJ, et al. Reliability and validity of the active straight leg raise test in posterior pelvic pain since pregnancy. Spine (Phila Pa 1976). 2001;26(10):1167-1171.

Mens JM, Vleeming A, Snijders CJ, et al. Validity of the active straight leg raise test for measuring disease severity in patients with posterior pelvic pain after pregnancy. Spine (Phila Pa 1976). 2002;27(2):196-200.

Mens JM, Vleeming A, Snijders CJ, et al. The active straight leg raising test and mobility of the pelvic joints. Eur Spine J. 1999;8(6):468-473.
Ng JK, Parnianpour M, Richardson CA, et al. Functional roles of abdominal and back muscles during isometric axial rotation of the trunk. J Orthop Res. 2001;19(3):463-471.

O'Sullivan PB, Beales DJ, Beetham JA, et al. Altered motor control strategies in subjects with sacroiliac joint pain during the active straight-leg-raise test. Spine (Phila Pa 1976). 2002;27(1):E1-E8.

Park KH, Ha SM, Kim SJ, et al. Effects of the pelvic rotatory control method on abdominal muscle activity and the pelvic rotation during active straight leg raising. Man Ther. 2013;18(3): 220-224

Potvin JR, Brown SH. An equation to calculate individual muscle contributions to joint stability. J Biomech. 2005;38(5):973-980.

Richardson CA, Jull GA. Muscle control-pain control. What exercises would you prescribe? Man Ther. 1995;1(1):2-10.

Snijders CJ, Vleeming A, Stoeckart R. Transfer of lumbosacral load to iliac bones and legs part 1: Biomechanics of self-bracing of the sacroiliac joints and its significance for treatment and exercise. Clin Biomech (Bristol, Avon). 1993;8(6): 285-294.

Souza GM, Baker LL, Powers CM. Electromyographic activity of selected trunk muscles during dynamic spine stabilization exercises. Arch Phys Med Rehabil. 2001;82(11): 1551-1557.

Stevens VK, Bouche KG, Mahieu NN, et al. Trunk muscle activity in healthy subjects during bridging stabilization exercises. BMC Musculoskelet Disord. 2006;7:75.

Stevens VK, Coorevits PL, Bouche KG, et al. The influence of specific training on trunk muscle recruitment patterns in healthy subjects during stabilization exercises. Man Ther. 2007;12(3): 271-279.

Sung PS. A compensation of angular displacements of the hip joints and lumbosacral spine between 
한국전문물리치료학회지 2013년 20권 3호 81-88

Phys Ther Kor 2013;20(3):81-88

subjects with and without idiopathic low back pain during squatting. J Electromyogr Kinesiol. 2013;23(3):741-745.

Teyhen DS, Williamson JN, Carlson NH, et al. Ultrasound characteristics of the deep abdominal muscles during the active straight leg raise test. Arch Phys Med Rehabil. 2009;90(5):761-767.

Vera-Garcia FJ, Elvira JL, Brown SH, et al. Effects of abdominal stabilization maneuvers on the
ISSN (Print) 1225-8962, ISSN (Online) 2287-982X http://dx.doi.org/10.12674/ptk.2013.20.3.081

control of spine motion and stability against sudden trunk perturbations. J Electromyogr Kinesiol. 2007;17(5):556-567.

This article was received July 24, 2013, was $\mathrm{re}^{-}$ viewed July 24, 2013, and was accepted September 3, 2013. 